\title{
LUMINESCENCE OF BISMUTH IN YTTRIUM ALUMINUM BORATE
}

\author{
F. KELLENDONK, M.A. VAN OS and G. BLASSE \\ Physical Laboratory, State Unil ersity, 3508 TA Utrecht, The Netherlands
}

Received 13 November 1978

The luminescence spectra of $\mathrm{Bi}^{3+}$ incorporated in yttrium aluminum borate are reported. At liquid helium temperature the emission band shows vibrational structure with equidistant lines. The efficiency of eneigy transfer from $\mathrm{Bi}^{3+}$ to $\mathrm{Tb}^{3+}$ and from $\mathrm{Ce}^{3+}$ to $\mathrm{Tb}^{3+}$ has also been measured. The energy transfer from $\mathrm{Bi}^{3+}$ to $\mathrm{Tb}^{3+}$ is more efficient than that from $\mathrm{Ce}^{3+}$ to $\mathrm{Tb}^{3+}$.

\section{Introduction}

The luminescence of the $\mathrm{Bi}^{3+}$ ion in inorganic compounds has been a subject of investigation for many years $[1,2]$. Usually the emission consists of a broad structureless band. The emission band shows vibrational structure, however, when bismuth is incorporated into some oxides with rock-salt structure [3-6].

In this letter we report on the luminescence characteristics of bismuth in yttrium aluminum borate $\left(\mathrm{YAl}_{3} \mathrm{~B}_{4} \mathrm{O}_{12}\right)$. We also compare the efficiency of energy transfer from bismuth to terbium with the efficiency of cerium-to-terbium transfer.

Yttrium aluminum borate is isostructural with huntite $\left(\mathrm{CaMg}_{3}\left(\mathrm{CO}_{3}\right)_{4}\right)[7,8]$. The yttrium ion is coordinated by a trigonal prism of oxygen ions (site symmetry $D_{3}$ ). When bismuth is incorporated into this compound it occupies the lattice site of the yttrium ion.

\section{Experimental}

Powder samples were prepared as described by Takahashi et al. [9] . Samples were checked by X-ray diffraction. Emission and excitation spectra were recorded on a Perkin-Elmer MPF 2A spectrofluorimeter. Excitation spectra were corrected for monochromator transmission and intensity of the exciting radiation.

\section{Results and discussion}

At room temperature the emission and excitation spectra show structureless bands with maxima at 34090 and $36925 \mathrm{~cm}^{-1}$, respectively (see fig. 1). According to Blasse and Brii [1] the excitation band corresponds to the ${ }^{1} \mathrm{~S}_{0}-{ }^{3} \mathrm{P}_{1}$ transition. The emission band must be due to the $3 \mathrm{P}_{1} \rightarrow{ }^{1} \mathrm{~S}_{0}$ transition, because the transition from the lowest excited state $\left({ }^{3} \mathrm{P}_{0}\right)$ to ${ }^{1} S_{0}$ is strongly forbidden [?]. Fig. 1 depicts also the excitation and emission spectra at $4.2 \mathrm{~K}$. The width of

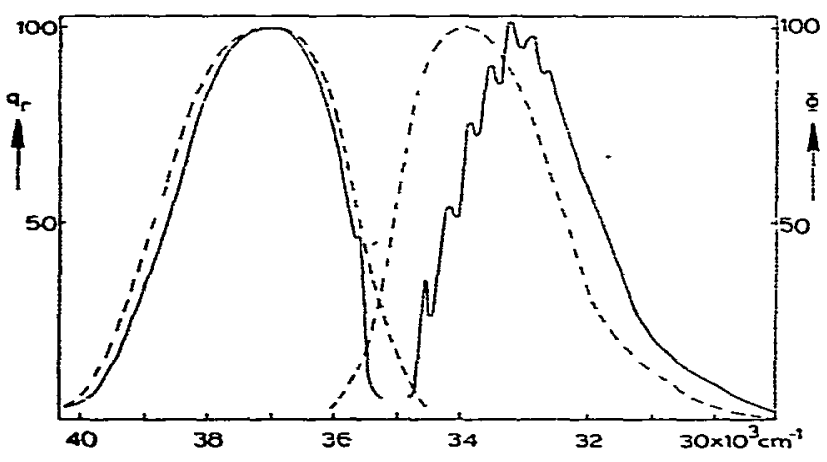

Fig. 1. Emission and evcitation spectra at room temperature (broken line) and at liquid helium temperature (full line). The emission spectra are recorded under $38500 \mathrm{~cm}^{-1}$ excitation. The excitation spectra are measured for the emission at 32000 $\mathrm{cm}^{-1}$. $\Phi$ denotes the spectral radiant power per unit energy in arbitrary units and $q_{\mathrm{I}}$ denotes the relative quantum output. 
the excitation band decreases slightly to lower temperatures, and a line appears at the low-energy side of the band. This line is probably the zero-phonon line. The position of the band is temperature independent. The influence of temperature on the emission spectrum is more pronounced. At liquid helium temperature the emission band shows vibrational structure with equidistant lines. The distance between the lines is ( 330 $\pm 10) \mathrm{cm}^{-1}$. To our knowledge the host lattices in which $\mathrm{Bi}^{3+}$ shows an emission band with vibrational structure have rock-salt or related crystal structures [3-6]. The structure of yttrium aluminum borate is strongly different, which means that the appearance of vibronic lines in the $\mathrm{Bi}^{3+}$ emission is not restricted to the rock-salt lattice.

Because the first line in the vibronic spectrum is quite sharp in comparison with the other lines, it is assigned to the zero-phonon transition. Its spectral position is different from the zero-phonon line in the excitation spectrum. This implies that the emission must originate from the lowest excited level $\left({ }^{3} \mathrm{P}_{0}\right)$. We have tried to measure decay times to confirm this assignment, but due to the small Stokes shift it was not possible to separate excitation and emission radiation with the present set-up.

The energy separation between the ${ }^{3} \mathrm{P}_{0}$ and ${ }^{3} \mathrm{P}_{1}$ states can be found from the spectral distance between the two zero-phonon lines and amounts to $1080 \mathrm{~cm}^{-1}$. This value compares reasonably with the separation between the ${ }^{3} \mathrm{P}_{\mathrm{O}}$ and ${ }^{3} \mathrm{P}_{1}$ levels of $\mathrm{Bi}^{3+}$ in $\mathrm{CaO}(1200$ $\mathrm{cm}^{-1}$ ) found by Hughes and Pells [4].

The occurrence of a zero-phonon line in the structured emission band, corresponding to the strongly forbidden ${ }^{3} \mathrm{P}_{0} \rightarrow{ }^{1} \mathrm{~S}_{0}$ transition, is unexpected (in $\mathrm{D}_{3}$ symmetry it is an $A_{1} \rightarrow A_{1}$ transition which is only allowed as an electric quadrupole transition). Hughes and Pells [4] have given an explanation for the presence of a zero-phonon line in the emission spectra of $\mathrm{Bi}^{3 *}$ in alkaine earth oxides: Static symmetry-reducing perturbations can also release selection rules. These perturbations are due to strains in the crystal lattice caused by charged defects. The incorporation of $\mathrm{Bi}^{3+}$ or a $\mathrm{Mg}^{2+}$ or $\mathrm{Ca}^{2+}$ site must be accompanied by the formation of a charge-compensating defect. In yttrium aluminum borate, however, there is no need for charge compensating defects. For this reason it is not clear if in this case the static perturbation mechanism is valid. We will investigate this further on single crystals.
Table 1

Ratio of the terbium to sensitizer quantum output as a funetion of $x$ in $Y_{0.99}-x^{\mathrm{Tb}} 0.01 \mathrm{M}_{x} \mathrm{Al}_{3} \mathrm{~B}_{4} \mathrm{O}_{12}(\mathrm{M}=\mathrm{Ce}$ or $\mathrm{Bi})$

\begin{tabular}{lll}
\hline$x$ & $q \mathrm{~Tb} / q \mathrm{Ce}$ & $q \mathrm{~Tb} / q \mathrm{Bi}$ \\
\hline 0.1 & 0.055 & 0.149 \\
0.2 & 0.059 & 0.408 \\
0.3 & 0.062 & 0.634 \\
0.4 & & 1.417 \\
0.5 & & 2.500 \\
\hline
\end{tabular}

Efficiencies for energy transfer from $\mathrm{Bi}^{3+}$ to $\mathrm{Tb}^{3+}$ and from $\mathrm{Ce}^{3+}$ to $\mathrm{Tb}^{3+}$ were measured on the following compositions $\mathrm{Y}_{0.99-x} \mathrm{~Tb}_{0.01} \mathrm{M}_{x} \mathrm{Al}_{3} \mathrm{~B}_{4} \mathrm{O}_{12}$ (M $=\mathrm{Ce}$ or $\mathrm{Bi}$ ). The maximum amounts of $\mathrm{Ce}^{3+}$ and $\mathrm{Bi}^{3+}$ that could be substituted for $\mathrm{Y}^{3+}$ are 30 and $50 \%$, respectively. Excitation was into the maxima of the respective excitation bands $\left(31250 \mathrm{~cm}^{-1}\right.$ for $\mathrm{Ce}^{3+}$ and $36925 \mathrm{~cm}^{-1}$ for $\left.\mathrm{Bi}^{3+}\right)$. The ratio of the terbium and the sensitizer quantum outputs $\left(q_{\mathrm{Tb}} / q_{\mathrm{M}}\right)$ were measured at room temperature. The results are compiled in table 1 .

It follows that energy transfer in the bismuth compositions is more efficient than in the cerium compositions. In the case of cerium to terbium transfer the ratio $q_{\mathrm{Tb}} / q_{\mathrm{Ce}}$ is independent of the cerium concentration within the experimental error. This indicates that $\mathrm{Ce}^{3+}$ to $\mathrm{Ce}^{3+}$ transfer does not play an important role. Assuming efficient transfer between nearest neighbours only and neglecting $\mathrm{Ce}^{3+}$ to $\mathrm{Ce}^{3+}$ transfer we have

$q_{\mathrm{Tb}} / q_{\mathrm{Ce}}=\left[1-\left(1-x_{\mathrm{Tb}}\right)^{k}\right] /\left(1-x_{\mathrm{Tb}}\right)^{k}$,

where $k$ is the number of nearest neighbours in the yttrium sublattice and $x_{T b}$ the terbium concentration. With $k=6$ and $x_{T 0}=0.01$ this ratio is 0.062 , in good agreement with the experimental values. This supports our assumptions.

In the case of $\mathrm{Bi}^{3+}$ to $\mathrm{Tb}^{3+}$ transfer there is an increase of the ratio $q_{\mathrm{Tb}} / q_{\mathrm{Bi}}$ with increasing $\mathrm{Bi}^{3+}$ concentration indicating the importance of bismuth to bismuth transfer. The mechanism of these energy transfers will be subject of further investigations.

\section{Acknowledgement}

This investigation was performed as a part of the research program of the "Stichting voor Fundamenteel 
Onderzoek der Materie (F.O.M.)" with financial support from the "Nederlandse Organisatie voor ZuiverWetenschappelijk Onderzoek (Z.W.O.)".

\section{References}

(1) G. Blasse and A. Bril, J. Chem. Phys. 48 (1968) 217.

[2] G. Boulon, J. Phys. (Paris) 32 (1971) 333.
[3] A.E. Hughes and G.P. Pells, Phys. Stat. Sol. 25a (1974) 437.

[4] A.E. Hughes and G.P. Pells, Phys. Stat. Sol. 71 v (1975) 707.

[5] A.F. Ellervee, Phys. Stat. Sol. 82b (1977) 91.

[6] A.C. van der Steen, J.J.A. van Hesteren, A. Roos and G. Blasse, J. Luminescence 18/19 (1979) 235.

[7] A.A. Ballman, Am. Mineralogist 47 (1962) 1380.

[8] A D. Müls, Inorg. Chem. 1 (1962) 960.

[9] T. Takahashi and O. Yamada, J. Electrochem. Soc. 124 (1977) 995. 